\title{
ENTREPRENEURIAL ORIENTATION DAN PENGALAMAN KERJA
}

\author{
ARLIKA ANINDYA PUTRI \\ FAKULTAS BISNIS DAN EKONOMIKA, UNIVERSITAS SURABAYA
}

Entrepreneurial Orientation perilaku perusahaan dalam postur atau sikap perusahaan dalam mengembangkan produk atau jasa, maupun dalam mengadopsi teknologi yang baru, meliputi frekuensi sejauh mana inovasi dalam organisasi (Pratono, 2016). Proaktif adalah kesediaan untuk membedakan ide ide dari peluang melalui penelitian, analisis, peramalan kecenderungan pasar.

Pengambilan Keputusan (Risk-Taking) adalah salah satu dimensi lain yang penting untuk EO mencakup resiko penerimaan dalam hal investasi dan keputusan strategis bahkan jika pengeluaran dari tindakan tersebut tidak pasti atau tidak tentu. Keberanian mengambil risiko ini berarti juga menunjukan kemampuan untuk mengontrol dan mengevaluasi resiko (Franco \& Haase, 2013; Pratono, 2018).

Inovasi menggambarkan bahwa kecenderungan sebuah perusahaan untuk terlibat dan mendukung ide ide baru, originalitas, ekperimen atau percobaan dan proses kreatif yang dapat menghasilkan produk, jasa ataupun proses teknologi yang baru (Pratono, 2018). EO identik oleh perilaku pengambilan keputusan, dapat menimbulkan pinjaman yang berat atau membuat sumber daya yang signifikan dan dapat berkomitmen dalam kepentingan untuk memperoleh sesuatu yang di harapkan setinggi-tingginya dalam merebut peluang di pasar (Pratono et al, 2018). Proaktif dalam mencari peluang/ kesempatan ditandai dengan memperkenalkan produk\&jasa baru dalam persaingan yang sehat dan bertindak dalam rangka mengantisipasi permintaan di masa mendatang.

Kompetitif agresif menggambarkan intensitas usaha suatu perusahaan untuk mengalahkan atau mengungguli persaingan industri lainnya, ditandai dengan perilaku serangan kuat dan respon yang kuat dari perilaku pesaing. Autonomi adalah tindakan independen suatu individu atau kelompok yang bertujuan untuk membuat konsep bisnis atau pandangan dan membawanya melalui penyelesaian. (Caseiro \& Coelho, 2018)

Kompetitif merupakan kemampuan individual perusahaan (atau seluruh sektor, region, dan bahkan negara) untuk menegaskan dirinya agar dapat berhasil di pasar domestik maupun pasar global. kompetitif itu tidak selalu tentang kegiatan kewirausahaan dari perusahaan individual, tetapi juga sesuai hasil kebijakan struktural, kebijakan berfungsi kompetitif dan infrastruktur yang memadai. (Soininen, Puumalainen, Sjogren, Syrja, \& Durst, 2013) 
Kinerja Perusahaan merupakan ukuran tingkat efisiensi suatu perusahaan dalam mengoperasikan perusahaannya. kita dapat mengetahui kinerja perusahaan melalui menanyakan kepada responden untuk membandingkan kinerja perusahaan relatif yang di milikinya dengan pesaingnya dalam delapan perbedaan dimensi untuk tahun sebelumnya (pertumbuhan sebelumnya, laba investasi, laba penjualan dan sebagainya) menggunakan skala dari 1 sampai 7. (Lizou \& Hinterhuber, 2013; Pratono et al, 2018)

Faktor karakterisik perusahaan seperti Ukuran Perusahaan, R\&D Intensitas, Intensitas Modal, dan Debt Leverage umumnya digunakan untuk mengontrol efek asing atau efek luar. berikut ini dipertimbangkan untuk mengontrol variabel: Ukuran Perusahaan. ini dapat dilihat sebagai salah satu yang menjadi factor penentu dalam keuntungkan perusahaan dimana dapat ber-efek kepada Competitive Market Power.

Pengeluaran R\&D hasil dari produk dan teknologi baru yang dapat membantu mengembangkan perusahaan, dapat menopang keunggulan kompetitif, mendapatkan tambahan pangsa pasar dan dapat menembus pasar baru. Intensitas Modal dominannya kepada investasi keuangan dalam teknologi, mesin dan peralatan sebagai arti untuk mengurangi biaya tenaga kerja dalam operasi (Pratono et al, 2017). Debt Leverage. menangkap risiko keuangan sebagai utang terhadap rasio kekayaan. Ukuran Perusahaan, Intensitas R\&D dan Intensitas Modal merupakan berkaitan dengan kinerja perusahaan melalui tinggi dan rendahnya industri. sedangkan, Debt Leverage diasosiasikan negatif melalui tinggi dan rendahnya industri. (Lee \& Roh, 2012)

Instrumen yang meliputi kinerja perusahaan adalah meningkatkan tingkat penjualan atau pendapatan, operasi dari arus kas, laba investasi, laba modal, market share, pengembangan produk baru, perkembangan pasar, kualitas dari produk dan jasa, dan sebagainya. (Teeratansirikool, Siengthai, Badir, \& Chotchai, 2013) perbedaan gender memiliki dampak positif dalam kinerja perusahaan. Ada beberapa alasan mengapa kita harus mengharapkan perbedaan, khususnya perbedaan gender dari dewan direksi, untuk menggunakan dampak positif dalam kinerja perusahaan.

Pertama, diasumsikan sebuah badan heterogen akan lebih memahami pasar, dan oleh karena itu segmentasi pasar membutuhkan untuk produk atau jasa, dengan potensi efek positif dalam kinerja. di samping itu, akan menjadi kreativitas tinggi dan inovasi dibawah badan heterogen. Kedua, perbedaan lebih tinggi dapat mengarah pada corporate image yang lebih baik dan untuk menjadikan kinerja yang lebih tinggi. Efek dari perbedaan gender dalam kinerja perusahaan ini rentan dengan kepercayaan untuk mengukur perbedaan dan pemilihan kriteria kinerja. (Solakoglu \& Demir, 2016)

\section{KINERJA PERUSAHAAN}

EO merupakan sumber daya yang dapat meningkatkan kinerja perusahaan dan minat dalam proses kognitif yang berfungsi sebagai sumber daya yang dapat menggantikan 
selaras dengan EO dan dapat membantu meningkatkan kinerja perusahaan. Ketertarikan dalam pekerjaan secara positif adalah perantara dari hubungan antara EO dan kinerja perusahaan, untuk memahami batas kondisi dan peranan dari minat untuk bekerja pada hubungan EO dan kinerja perusahaan.

Hubungan antara EO dan kinerja perusahaan yang dianggap untuk menjadi lebih kuat dalam manajer tingkat tinggi untuk semangat dalam bekerja, dan dapat dijadikan perantara dalam pengaruh dari hubungan EO terhadap kinerja perusahaan lebih kuat ketika lingkungan berada dalam keadaan yang berubah (Pratono \& Mahmood, 2015). Keuntungan dari perusahaan EO terlepas dari kondisi dimana mereka mengoperasikan benefit yang didapat dengan pemahaman tentang EO dan hubungannya dengan kinerja perusahaan (Adomako, Quartey, \& Narteh, 2016). Kekuatan hubungan antara EO dan kinerja perusahaan mungkin bisa tergantung dari karakteristik lingkungan luar bisnis, termasuk lingkungan petentangan dan pertumbuhan pasar terhadap hasil produk dan jasa suatu perusahaan (Pratono et al, 2018).

Hubungan antara EO dan kinerja perusahaan dikelola oleh lingkungan pertentangan, seperti kinerja perusahaan meningkat sehingga EO berada di tingkat yang lebih cepat untuk perusahaan yang beroperasi dalam lingkungan bertentangan (Pratono \& Mahmod, 2015). Hubungan antara EO dan kinerja perusahaan dikelola oleh pertumbuhan pasar, sehingga kinerja perusahaan meningkat dengan adanya EO pada tingkat yang lebih lambat untuk perusahaan yang merasakan pertumbuhan pasar untuk hasil produk dan jasa yang mereka miliki.

Kinerja perusahaan dijelaskan dengan konfigurasi dari EO dalam kombinasi dengan lingkungan pertentangan dan pertumbuhan pasar, seperti suatu perusahaan menerima kinerja lebih tinggi dengan level tertinggi dari EO dalam lingkungan pertentangan dengan pertumbuhan pasar yang rendah dan kinerja yang rendah dengan level tertinggi EO dalam lingkungan yang tidak ada pertentangan dengan pertumbuhan pasar, dibandingkan kepada konfigurasi lain (Shirokova, Bogatyreva, Beliaeva, \& Puffer, 2016)

Efek penunjang dari EO dalam kinerja melalui kemampuan pemasaran yang dikelola oleh sumber daya pemasaran, seperti efek penunjang dapat lebih kuat ketika sumber daya pemasaran yang tinggi dan pada saat situasi menurun. (Sok, Snell, Lee, \& Sok, 2017). Peran penting dari aspek internal perusahaan dalam hubungan EO dan keseluruhan kinerja perusahaan. namun, studi ini memiliki perbedaan perspektif dalam aspek internal perusahaan dan memiliki 2 konsekuensi yang serius. pertama, fokus kepada set terbatas dalam aspek internal perusahaan dan oleh karena itu jangan membandingkan pengaruh dari 2 tipe yang berbeda dari aspek perusahaan dalam hubungan EO-kinerja perusahaan. kedua, memiliki kategori berbeda dari aspek perusahaan, sebagai contohnya aspek internal perusahaan dari berbagai penelitian tidak dapat dengan mudah dikombinasikan untuk membuat ringkasan (Pratono, 2015). Masalah yang dihasilkan dalam membandingkan dan menggabungkan hasil dari memisahkan penelitian yang sangat menghambat karya dari kumpulan pengetahuan tentang bagaimana EO mempengaruhi kinerja perusahaan (Rezaei \& Ott, 2018) 


\section{Pengalaman KerJa}

Kekuatan pengalaman untuk berbagi pengalaman pribadi yang unik dan bersifat pengalaman wirausaha dan nilai-nilai penguasaha dalam menampilkan kepada mereka untuk mempelajari dari keluarga atau belajar dari orang lain sebelum memulai mendirikan usahanya sendiri. dianjurkan untuk pelajar agar mencerminkan dari pengalaman pribadinya sendiri dalam memaparkan untuk bisnis keluarga atau ide bisnis yang mungkin kondusif dalam sesi pendidikan entrepreneurship. Studi ini diidentifikasi pengalaman pribadi dari inspirasi dan komitmen, kesulitan, work ethic, sumber daya dan mereka berupaya agar dapat bermanfaat bagi pelajar pada perkembangan terhadap start up mereka bisnis (Tarling, Jones, \& Murphy, 2016)

Melalui pasar diferensiasi serta inovasi, perusahaan akan mampu mencapai keunggulan kompetitif dan dapat meningkatkan kinerja bisnis. model ini juga berkaitan langsung dengan pengalaman kerja dan kinerja bisnis. Argumentasi memiliki inovasi diferensiasi dalam bisnis termasuk pengembangan produk, produksi baru metode dan proses baru , yang di dalamnya dapat memberikan keuntungan finansial. (Grønholdt, Martensen, Jørgensen, \& Jensen, 2015). Dalam pengalaman bekerja kita harus memiliki kerangka kerja terlebih dahulu untuk dapat memahami bagaimana pengusaha menjalankan pekerjaannya dengan baik, pada masa kerja berhubungan dengan generasi ide baru, dengan menggabungkan teori sumber daya manusia dengan adanya teori dan penelitian sumber daya manusia tentang belajar menjadi pengusaha yang sukses (Pratono \& Mahmood, 2015).

Pengalaman dalam melakukan fungsi bisnis tertentu dapat memberikan pelatihan individu dalam kegiatan bisnis itu penting seperti dalam perencanaan, pengorganisasian dan berkomunikasi. Ide-ide usaha baru berasal dari kesalahan persepsi tiap harinya dalam produksi, investasi, distribusi dan lain sebagainya. Yang pada akhirnya dapat menyebabkan pemahaman yang lebih baik tentang sumber daya yang dikoordinasikan merupakan sebuah sarana yang efektif. Oleh karena itu, sejauh mana setiap individu tidak akan mempunyai kekuasaan untuk merebut peluang, peluang yang bisa memberi manfaat bagi yang ingin memiliki usaha dan dapat menghasilkan ide-ide bisnis baru dapat dipengaruhi oleh kedua fungsi pengalaman industri dan bisnis (Pratono et al, 2018).

Kinerja terkait dengan pekerjaan memiliki keuntungan yaitu seseorang dapat belajar langsung dan mendapatkan hasil yang secara otomatis dihasilkan dari akumulasi pengalaman. penelitian ini berfokus mengenai pengaruh dalam proses belajar menjadi pengusaha yang sukses, dimana pengalaman terus-menerus diperoleh dan kemudian berubah menjadi pengetahuan. Disamping itu ditekankan dalam penelitian ini proses perubahan yang didapat adalah hasil tergantung pada cara dimana orang lebih memilih untuk belajar dari pengalaman. (Gabrielsson \& Politis, 2012) 


\section{BIBLIOGRAPHY}

Adomako, S., Quartey, S. H., \& Narteh, B. (2016). Entrepreneurial orientation, passion for work, perceived environmental dynamism and firm performance in an emerging economy. Journal of Small Business and Enterprise Development, 23 (3), 728-752.

Caseiro, N., \& Coelho, A. (2018). Business intelligence and competitiveness: the mediating role of entrepreneurial orientation. Competitiveness Review: An International Business Journal , 28 (2), 213-226.

Franco, M., \& Haase, H. (2013). Firm resources and entrepreneurial orientation as determinants for collaborative entrepreneurship. Management Decision, 51 (3), 680-696.

Gabrielsson, J., \& Politis, D. (2012). Work experience and the generation of new business ideas among entrepreneurs: An integrated learning framework. International Journal of Entrepreneurial Behavior \& Research, 18 (1), 48-74.

Grønholdt, L., Martensen, A., Jørgensen, S., \& Jensen, P. (2015). Customer experience management and business performance. International Journal of Quality and Service Sciences, 7 (1), 90-106.

Lee, J., \& Roh, J. J. (2012). Revisiting corporate reputation and firm performance link. Benchmarking: An International Journal , 19 (4/5), 649-664.

Lizou, S. M., \& Hinterhuber, A. (2013). Pricing orientation, pricing capabilities, and firm performance. Management Decision, 51 (3), 594-614.

Pratono, A. H., \& Mahmood, R. (2015). Mediating effect of marketing capability and reward philosophy in the relationship between entrepreneurial orientation and firm performance. Journal of Global Entrepreneurship Research, 5(5), 1-12.

Pratono, A.H. (2016). Strategic orientation and information technological turbulence: Contingency perspective in SMEs", Business Process Management Journal, 22(2), 368-382, https://doi.org/10.1108/BPMJ-05-2015-0066

Pratono, A.H. \& Tjahjono, G. (2017) "How does materialistic attitude influence the impact of corporate brand on the customers' intention to donate to corporates' charity?, Humanomics, 33(4), 484-498, https://doi.org/10.1108/H-07-2016-0052

Pratono, A.H., Suyanto, Marciano, D., \& Zurbrügg, C. (2017). Social return on investment for community-based enterprise in Surabaya City, The Hong Kong Journal of Social Work 51 (01n02), 93-114

Pratono, A.H., (2018) Does firm performance increase with risk-taking behavior under information technological turbulence?: Empirical evidence from Indonesian SMEs", The Journal of Risk Finance, 19(4), 361-378, https://doi.org/10.1108/JRF-10-20170170 
Pratono, A.H. (2018). From social network to firm performance: The mediating effect of trust, selling capability and pricing capability, Management Research Review 41 (6), 680-700

Pratono, A.H. (2018). Linking religiosity to citizenship behaviour under materialism attitude: Empirical evidence from Indonesia", International Journal of Ethics and Systems, https://doi.org/10.1108/IJOES-07-2018-0104

Pratono A.H. (2018). Network structure and open innovation: the role of trust in product development International Journal of Business Innovation and Research, 15 (1), 4461.

Pratono, A.H., Ratih, R.V.S., Arshad, D. (2018). Does Entrepreneurial Autonomy Foster SME Growth Under Technological Turbulence? The Empirical Evidence from Indonesia, Journal of Technology in Behavioral Science, 3(3), 170-178.

Rezaei, J., \& Ott, R. (2018). Entrepreneurial orientation and firm performance: the mediating role of functional performances. Management Research Review, 41 (7), 878-900.

Shirokova, G., Bogatyreva, K., Beliaeva, T., \& Puffer, S. (2016). Entrepreneurial orientation and firm performance in different environmental settings: Contingency and configurational approaches. Journal of Small Business and Enterprise Development, 23 (3), 703-727.

Soininen, J. S., Puumalainen, K., Sjogren, H., Syrja, P., \& Durst, S. (2013). Entrepreneurial orientation in small firms - values-attitudes-behavior approach. International Journal of Entrepreneurial Behavior \& Research , 19 (6), 611-632.

Sok, P., Snell, L., Lee, W. J., \& Sok, K. M. (2017). Linking entrepreneurial orientation and small service firm performance through marketing resources and marketing capability: A moderated mediation model. Journal of Service Theory and Practice, 27 (1), 231-249.

Solakoglu, M. N., \& Demir, N. (2016). The role of firm characteristics on the relationship between gender diversity and firm performance. Management Decision, 54 (6), 1407-1419.

Tarling, C., Jones, P., \& Murphy, L. (2016). Influence of early exposure to family business experience on developing entrepreneurs. Education + Training, 58 (7/8), 733-750.

Teeratansirikool, L., Siengthai, S., Badir, Y., \& Chotchai, C. (2013). Competitive strategies and firm performance: the mediating role of performance measurement. International Journal of Productivity and Performance Management, 62 (2), 168-184. 